\title{
Diagnostic value of investigating GNAS mutations in fibro-osseous lesions: a retrospective study of 91 cases of fibrous dysplasia and $\mathbf{4 0}$ other fibro-osseous lesions
}

\author{
Flore Tabareau-Delalande ${ }^{1,2}$, Christine Collin ${ }^{2}$, Anne Gomez-Brouchet ${ }^{3}$, \\ Anne-Valérie Decouvelaere ${ }^{4}$, Corinne Bouvier ${ }^{5}$, Frédérique Larousserie ${ }^{6}$, \\ Béatrice Marie $^{7}$, Christophe Delfour ${ }^{8}$, Sébastien Aubert ${ }^{9}$, Philippe Rosset $^{10}$, \\ Anne de Muret ${ }^{1}$, Jean-Christophe Pagès ${ }^{2}$ and Gonzague de Pinieux ${ }^{1,11}$
}

${ }^{1}$ Department of Pathology, Tours University Hospital and University François Rabelais, Tours, France;

${ }^{2}$ Laboratory of Biochemistry and Molecular Biology, Trousseau University Hospital and University François

Rabelais, Tours, France; ${ }^{3}$ Department of Pathology, Rangueil University Hospital, Toulouse, France;

${ }^{4}$ Department of Pathology, Léon Bérard Center, Lyon, France; ${ }^{5}$ Department of Pathology, La Timone

University Hospital, Marseille, France; ${ }^{6}$ Department of Pathology, Cochin University Hospital, Paris, France;

${ }^{7}$ Department of Pathology, University Hospital of Nancy, Nancy, France; ${ }^{8}$ Department of Pathology,

Caremeau University Hospital, Nîmes, France; ${ }^{9}$ Department of Biology-Pathology, University Hospital of

Lille II, Lille, France; ${ }^{10}$ Orthopedic Unit, Trousseau University Hospital and University François Rabelais,

Tours, France and ${ }^{11}$ INSERM, UMR 957, Laboratory for Bone Resorption Physiopathology and Primary

Bone Tumour Therapy, Faculty of Medicine, University of Nantes, Nantes, France

GNAS (guanine nucleotide-binding protein/ $\alpha$-subunit) mutations that induce the activation of G-protein $\alpha$-subunit participate in the pathogenesis of fibrous dysplasia. The aim of this study was to evaluate the sensitivity and specificity of GNAS mutations in fibrous dysplasia and other fibro-osseous lesions, to assess the value of investigating this mutation in the diagnosis of fibro-osseous lesions. We studied 91 cases of fibrous dysplasia. The quality and/or quantity of genomic DNA were suitable for molecular analysis for 51 cases of fibrous dysplasia. GNAS mutations were investigated by three techniques: high-resolution melting (exon 8), allele-specific PCR (exons 8 and 9) and/or direct DNA sequencing (exons 8 and 9). Fibrous dysplasia samples were classified blind to the GNAS mutation status into six histological subtypes as conventional, fibro-involutive, osteosclerosing, cementifying, osteocartilaginous and with prominent aneurysmal cystic changes. We also studied 14 cases of lowgrade osteosarcoma, 21 cases of ossifying fibroma, 3 cases of osteofibrous dysplasia, 1 case of osseous dysplasia of the jawbone and 1 post-traumatic lesion of the ribs. Twenty-three cases of fibrous dysplasia (45\%) showed mutations of codon 201 (exon 8, p.R201H or p.R201C). No mutation was found on codon 227 (exon 9). GNAS mutations in conventional fibrous dysplasia were detected in the same proportion $(47 \%)$ as in the other histological subtypes $(47 \%, P=0.96)$, regardless of sex $(P=0.44)$, age $(P=0.90)$ and location $(P=1)$. GNAS mutations were not detected in any other fibro-osseous lesions. The GNAS mutation was thus specific to fibrous dysplasia in the context of fibro-osseous lesions. The particular mosaicism of mutant and non-mutant cells within the lesion or the existence of other mutations not already described could explain the lack of GNAS mutation in cases of fibrous dysplasia. Investigating this mutation may constitute a valuable complementary diagnostic tool, despite its low sensitivity, particularly in unconventional morphologically different subtypes of fibrous dysplasia. Modern Pathology (2013) 26, 911-921; doi:10.1038/modpathol.2012.223; published online 1 February 2013

Keywords: fibrous dysplasia; GNAS mutation; low-grade osteosarcoma

Correspondence: Professor G de Pineux, MD, PhD, Service de Pathologie, CHU Tours, Hopital Trousseau, Avenue de la République, Tours 37044, France.

E-mail: depineux@med.univ-tours.fr

Received 18 October 2012; revised 15 November 2012; accepted 15 November 2012; published online 1 February 2013
Benign fibro-osseous lesions are a group of polymorphic bone disorders, characterized by the replacement of normal bone by a collagen-rich tissue, comprising fibroblast-like cells and variably abundant immature fibrillar bone. Benign fibro-osseous 
lesions include a spectrum of bone lesions, such as fibrous dysplasia, osteofibrous dysplasia and, more specifically, in jawbones, ossifying fibroma and osseous dysplasia. ${ }^{1-3}$ Because of frequent overlapping of clinical, radiological and microscopic features, such lesions can be difficult to distinguish from each other ${ }^{4}$ and also from lowgrade osteosarcomas, the malignant counterpart of fibro-osseous lesions of the bone. ${ }^{5,6}$ However, it is important to differentiate between these lesions, because their clinical evolutions are different and involve different treatments. ${ }^{7,8}$ Fibrous dysplasia is the most common benign fibro-osseous lesion. The precise prevalence of fibrous dysplasia is difficult to establish, because the disease is usually asymptomatic and it is thought to represent $5-7 \%$ of all benign bone tumors. ${ }^{9}$ Fibrous dysplasia is an intramedullar lesion, histologically characterized by a fibrous connective-tissue stroma containing ovoid or spindle cells with regular oval nuclei, in which trabeculae of woven bone are found, without osteoblastic rimming. ${ }^{10}$ The trabeculae of woven bone can be slender and curved, resembling letters of the alphabet, or can form small calcified spherules that mimic cement. These features render the diagnosis of ossifying fibroma difficult in craniofacial locations. ${ }^{11}$ Clinically, fibrous dysplasia may involve one bone (monostotic disease in approximately $85 \%$ of all cases) or several bones (polyostotic disease). In about $5 \%$ of all cases, polyostotic fibrous dysplasia may be associated with polyendocrinopathy and jagged café-au-lait spots in McCune-Albright syndrome. ${ }^{12-14}$ Fibrous dysplasia can also be associated with soft tissue myxomas in Mazabraud syndrome. ${ }^{15-17}$ This particular disease presentation is explained by somatic mosaicism involving an activating mutation of a signal-transduction G-protein, occurring postzygotically ${ }^{18,19}$ in pluripotent embryonic stem cells. ${ }^{20}$ Monostotic fibrous dysplasia, polyostotic fibrous dysplasia, McCuneAlbright syndrome and soft tissue myxoma coexisting with fibrous dysplasia result from the somatic mutation of the same GNAS gene (guanine nucleotide-binding protein/ $\alpha$-subunit). ${ }^{21,22}$ This gene is located on chromosome 20q13.3, encoding the $\alpha$-subunit of the heterotrimeric G (Gs $\alpha$ ) protein complex. ${ }^{23-26}$ Two main mutations have been identified within exon 8 of the GNAS gene. ${ }^{27}$ These mutations are substitutions in codon 201, leading to the replacement of an arginine by a histidine $(\mathrm{R} 201 \mathrm{H})$, or a cysteine (R201C). In rare cases, serine (R201S), ${ }^{28}$ leucine (R201L) ${ }^{29,30}$ and glycine (R201G) substitutions have been reported. ${ }^{31}$ Exceptional cases of fibrous dysplasia have been linked to mutation in exon 9, leading to the substitution of the glutamine at position 227 by a leucine, an arginine, a lysine or a histidine. ${ }^{32}$ All mutations lead to constitutive Gs $\alpha$ adenylate cyclase activity with overproduction of cyclic adenosine monophosphate (CAMP) in dysplastic cells. ${ }^{33}$
Increased levels of intracellular cAMP may induce overproduction of $\mathrm{c}$-fos, one of the two transcription factors forming AP-1, in turn leading to the deregulation of bone protein expression, with increased proliferation of osteogenic cells and inhibition of their maturation. ${ }^{34}$ Stimulation of osteoclastic resorption upon overproduction of IL-6 and IL-11 has also been observed in dysplastic cells. ${ }^{35}$ Altogether, this leads to the formation of immature dysplasic bone. GNAS mutation has not been described in other types of benign fibroosseous lesions. ${ }^{11,36,37}$ However, one case of GNAS-mutated low-grade osteosarcoma has been reported in the literature ${ }^{38}$ (one case of R201C GNAS mutation in a femoral low-grade osteosarcoma, in a series of five low-grade osteosarcomas mimicking fibrous dysplasia).

There are several methods to detect GNAS mutation from paraffin-embedded tissues or frozen samples, ie, Sanger direct sequencing, ${ }^{39}$ restriction fragment-length polymorphism from PCR, ${ }^{11,36,37}$ an allele-specific probe for PCR quantification, ${ }^{40}$ PCR with mutation-specific restriction enzyme digestion, ${ }^{32}$ allele-specific PCR, ${ }^{24}$ coamplification at lower denaturation temperature PCR, ${ }^{26}$ HRM combined with direct sequencing and, more recently, pyrosequencing. ${ }^{41}$ The sensitivity of these techniques is variable and GNAS mutations remain unidentified in many fibrous dysplasia lesions, regardless of the molecular method used..$^{28,32,39}$

The aim of this study was to assess the value of routine detection of GNAS mutations to differentiate fibrous dysplasia from other benign fibro-osseous lesions and low-grade osteosarcoma, by (i) evaluating the sensitivity of detection of GNAS mutation in fibrous dysplasia, (ii) confirming the specificity of this mutation in fibrous dysplasia and (iii) correlating GNAS mutation status with clinical and histopathology findings.

\section{Materials and methods}

\section{Selection of Patients and Samples and DNA Extraction}

Institutional ethical guidelines were followed for this retrospective study. Between 2000 and 2012, a total of 91 cases of fibrous dysplasia were diagnosed histologically in the University Hospital of Tours (France), including 43 cases of fibrous dysplasia referred by other centers for second diagnosis opinion. Only two patients had a polyostotic form of fibrous dysplasia and the others had monostotic fibrous dysplasia. To select the most representative formalin-fixed and paraffin-embedded tissues, hematoxylin-eosin and saffron slides were reviewed by two pathologists (GdP and FTD) before the molecular studies. Genomic DNA (gDNA) was extracted using the QIAamp DNA formalin-fixed and paraffin-embedded extraction kit (QIAGEN) from $10-\mu \mathrm{m}$ sections cut from tissue blocks in 81 
cases and from snap-frozen tissue (stored at $-80^{\circ} \mathrm{C}$ ) in 18 cases, using the QIAamp DNA Mini Kit (QIAGEN). Tissue blocks and snap-frozen samples were available for eight tumors. Thick sections of formalin-fixed and paraffin-embedded tissue were dewaxed by extraction in $100 \%$ xylene and washed with $100 \%$ ethanol. The samples were air-dried before DNA extraction. The extracted DNA was quantified using a Spectrophotometer (Cary100Scan, Varian). In 40 cases, the DNA extracted was not suitable for molecular study (all from formalin-fixed and paraffin-embedded tissues), leaving only 51 cases of fibrous dysplasia available for analysis. In parallel, we studied 26 benign fibro-osseous lesions, including 21 cases of ossifying fibroma, 3 cases of osteofibrous dysplasia, 1 case of osseous dysplasia, 1 post-traumatic fibro-osseous lesion of the ribs (all from paraffin-embedded tissue, except for 1 osteofibrous dysplasia from a frozen sample) and 14 low-grade osteosarcomas (12 from formalin-fixed and paraffin-embedded tissue, and 2 from frozen tissues), with suitable DNA for each case.

\section{High-Resolution Melting (HRM) Analysis}

HRM screening for GNAS mutations was performed on a LightCycler 480 II (Roche) using the LightCycler 480 High Resolution Melting Master Kit (Roche). Each reaction contained $10 \mu \mathrm{l}$ of $2 \times$ Master Mix, $2.4 \mu \mathrm{l}$ of $25 \mathrm{mM} \mathrm{MgCl}_{2}, 0.4 \mu \mathrm{l}$ of each $10 \mu \mathrm{M}$ primer and $2 \mu \mathrm{l}$ DNA (30 ng), in a total volume of $20 \mu \mathrm{l}$. The GNAS HRM primers were: forward $5^{\prime}$-TCCATTGACCTCAATTTTGTTTCAG- $3^{\prime}$ and reverse $\quad 5^{\prime}$-AAGTTGACTTTGTCCACCTGGAACT-3' (Invitrogen). The final product size was $96 \mathrm{bp}$. The cycling conditions were $95{ }^{\circ} \mathrm{C}$ for $5 \mathrm{~min}$, followed by 50 cycles at $95{ }^{\circ} \mathrm{C}$ for $15 \mathrm{~s}, 68^{\circ} \mathrm{C}$ for $15 \mathrm{~s}$ and $72^{\circ} \mathrm{C}$ for $20 \mathrm{~s}$. The melting conditions included one cycle at $95^{\circ} \mathrm{C}$ for $1 \mathrm{~min}, 40^{\circ} \mathrm{C}$ for $1 \mathrm{~min}$ and $65^{\circ} \mathrm{C}$ for $2 \mathrm{~s}$, followed by an increase in temperature from $65^{\circ} \mathrm{C}$ to $95^{\circ} \mathrm{C}$ at $1{ }^{\circ} \mathrm{C} / \mathrm{s}$. All samples were tested in duplicate. Data were analyzed with the LightCycler 480 SW1.5 software, the normalized melting curves were established for each sample, and samples were compared with controls in a deduced difference plot. Significant deviations from the horizontal line in relation to the curve of the wild-type controls were indicative of sequence changes within the amplicon analyzed. The samples with distinct melting curves compared with the wild-type allele were recorded as positive for a mutation. All mutated samples were confirmed by direct sequencing (20 cases).

\section{Allele-Specific PCR}

Allele-specific PCR for GNAS R201 (exon 8) and GNAS L227 (exon 9) mutations were performed on a LightCycler 480 II (Roche) using the LightCycler 480 SYBR Green I Master kit (Roche). The primers
Table 1 Allele-specific PCR primers used for GNAS mutation detection

\begin{tabular}{ll}
\hline Primer name & Sequence \\
\hline GNAS-WT201-F & 5'-TCAGGACCTGCTTCGCTGCC-3' $^{\prime}$ \\
GNAS-R201H-F & 5'-CAGGACCTGCTTCGCTGCCA-3' $^{\prime}$ \\
GNAS-R201C-F & $5^{\prime}$-TCAGGACCTGCTTCGTGCT-3' \\
GNAS-201-R & $5^{\prime}$-AAGTTGACTTTGTCCACCTGGAACT-3' \\
GNAS-WT227-F & 5'-ATGTTTGACGTGGGTGGCCA-3' $^{\prime}$ \\
GNAS-L227Q-F & 5'-ATGTTTGACGTGGGTGGCCT-3' $^{\prime}$ \\
GNAS-227-R & $5^{\prime}$-TGGCCACCACGAAGATGATG-3' \\
\hline
\end{tabular}

Abbreviation: GNAS, guanine nucleotide-binding protein/ $\alpha$-subunit.

used for the allele-specific PCR are summarized in Table 1.

Each allele-specific PCR reaction contained $10 \mu \mathrm{l}$ of $2 \times$ SYBR Green master mix, $1 \mu \mathrm{l}$ of each $10 \mu \mathrm{M}$ primer and $50 \mathrm{ng}$ gDNA in a total volume of $20 \mu \mathrm{l}$. The cycling conditions were $95^{\circ} \mathrm{C}$ for $9 \mathrm{~min}$, followed by 45 cycles at $95^{\circ} \mathrm{C}$ for $10 \mathrm{~s}, 68^{\circ} \mathrm{C}$ for $10 \mathrm{~s}$ and $72{ }^{\circ} \mathrm{C}$ for $10 \mathrm{~s}$. The melting conditions included one cycle at $95^{\circ} \mathrm{C}$ for $5 \mathrm{~s}, 65^{\circ} \mathrm{C}$ for $1 \mathrm{~min}$ and $97^{\circ} \mathrm{C}$ for $15 \mathrm{~s}$. All samples were tested in duplicate. Data were analyzed with the LightCycler 480 SW1.5 software. All mutated samples were confirmed by direct sequencing (11 cases).

\section{PCR Amplification and Direct Sequencing Reaction}

Samples defined as mutated by HRM or allelespecific PCR were sequenced. PCR was performed using the following primers: forward $5^{\prime}$-TGACTATG TGCCGAGCGA- $3^{\prime}$ and reverse $5^{\prime}$-CCACGTCAAACA TGCTGGTG-3' (Invitrogen). The reaction contained $2 \mu \mathrm{l}$ of $10 \times$ polymerase buffer, $1.2 \mu \mathrm{l}$ of $25 \mathrm{mM}$ $\mathrm{MgCl}_{2}, 0.4 \mu \mathrm{l}$ of $10 \mathrm{mM}$ dNTP, $1 \mu \mathrm{l}$ of each $10 \mu \mathrm{M}$ primer, 1 unit of AmpliTaq Gold DNA Polymerase (Applied Biosystems) and $100 \mathrm{ng}$ of gDNA in a total volume of $20 \mu \mathrm{l}$. The PCR conditions were: $9 \mathrm{~min}$ at $94{ }^{\circ} \mathrm{C}, 30$ cycles of $30 \mathrm{~s}$ at $94{ }^{\circ} \mathrm{C}, 30 \mathrm{~s}$ at $48^{\circ} \mathrm{C}$ and $45 \mathrm{~s}$ at $72{ }^{\circ} \mathrm{C}$, followed by $7 \mathrm{~min}$ at $72{ }^{\circ} \mathrm{C}$. PCR products were purified with ExoSap-IT (GE Healthcare) according to the manufacturer's instructions. The sequencing reaction was performed using Big Dye terminator V3.1 cycle sequencing kit (Applied Biosystems), according to the manufacturer's protocol and using the above primers. The sequencing products were ethanol-precipitated before running on a Genetic Analyzer (Applied Biosystems). The sequencing data were analyzed using the Sequencing Analysis software (Applied Biosystems).

\section{Review of Slides}

In conjunction with molecular analysis, fibrous dysplasia hematoxylin-eosin and saffron slides were reviewed independently by two pathologists (GdP and FTD) blinded to the GNAS mutation status. Each case of fibrous dysplasia was classified 
among six histological subtypes: conventional, fibro-involutive, osteosclerosing, cementifying, osteocartilaginous and with prominent aneurysmal cystic changes.

\section{Fibrous Dysplasia Histological Subtypes}

The conventional form corresponded to fibrillar immature bony trabeculae distributed in a fibrous paucicellular background. Bony trabeculae showed a typical 'letters of the alphabet' pattern, without osteoblastic rimming (Figure 1a). Fibrous tissue contained small spindle or oval cells with indistinct cytoplasmic contours and with regular ovoid nuclei (Figure 1b). The fibro-involutive form was defined by the abundance of fibrous tissue, low cellular density, and rare and sparse osteogenesis, limited to a few short trabeculae of woven bone (Figure 1c). This form was frequently accompanied by edematous interstitial imbibition responsible for microcystic changes (Figure 1d). The osteosclerosing form was characterized by abundant Pagetoid-like osteogenesis, comprising thick trabeculae of 'normalized' bone, with predominantly mature lamellar architecture and poor cellular fibrous tissue (Figure 1e). This subtype included the liposclerosing myxoid-fibrous tumor, which is a specific anatomo-clinical fibrous dysplasia variant, located at the upper end of the femur (intertrochanteric region). The osteocartilaginous form was defined by conventional fibrous dysplasia containing lobules of hyaline cartilage with peripheral enchondral ossification (Figure 1f). The cartilaginous component was sometimes abundant, in particular in the polyostotic form. The cementifying form corresponded to cellular fibrous tissue with disperse small spherules looking like psammomatoid bodies (cementum-like material calcified to a greater or lesser degree, Figure 1g). The aneurysmal cystic form was defined by the presence of prominent hemorrhagic suffusions that might appear cystic, with osteoclast-like giant cells (Figure 1h). This subtype excluded fractured fibrous dysplasia.

\section{Statistical Analysis}

The sensitivity and specificity of the detection of GNAS mutations were evaluated in fibrous dysplasia, benign fibro-osseous lesions and low-grade osteosarcoma. Pearson $\chi^{2}$ and Mann-Whitney's tests were performed to analyze the relationships between the anatomo-clinical data of the two groups (presence or absence of GNAS mutations). XLStat software was used for statistical analysis (Addinsoft, Paris, France). $P$-values less than 0.05 were considered significant.

\section{Results}

\section{Clinical and Pathology Findings}

Patients with fibrous dysplasia. The aim of the study presented here was to analyze clinical and pathological data from 51 patients with fibrous dysplasia, for whom the quantity/quality of extracted gDNA allowed molecular analysis (Table 2). Ages ranged from 7 to 72 years (mean 33 years). The male-to-female ratio was 0.76 (male 22; female 29). Disease location for 10 patients was craniofacial and for 34 patients it was extra-craniofacial. The most frequent extra-craniofacial site was the femur $(n=16)$, followed by the radius $(n=5)$, tibia $(n=4)$, spine $(n=2)$ and pubic bone $(n=2)$. Among the craniofacial cases, four were located in the maxilla or the mandible, three in the skull, two in the orbit and one in the frontal sinus. Two patients had a polyostotic form: a 12-year-old girl, with hemimelic disease (patient 13) and a 48-year-old man with diffuse polyostotic disease, causing multiple severe bone deformations (patient 14).

Histologically, 19 patients had a conventional fibrous dysplasia form, and 30 were interpreted as unconventional: 14 fibro-involutive, 8 osteosclerosing (including one liposclerosing myxoid-fibrous tumor), 4 aneurysmal cystic, 3 cementifying and 1 osteocartilaginous fibrous dysplasia (Table 3).

Patients with other benign fibro-osseous lesions (ossifying fibroma, osteofibrous dysplasia, osseous dysplasia, post-traumatic fibro-osseous lesion of the ribs). All these lesions were diagnosed as morphologically typical. Mean age for patients with ossifying fibroma was 27 years (range 1 to 68 years) and the sex ratio was 0.75 ( 9 females to 12 males). The most frequently observed site was the mandible (8/ 18 cases), followed by the maxilla ( 5 cases) and the facial sinus (4 cases). One patient had a juvenile variant form of ossifying fibroma, with recurrence in the eye socket a few months after enucleation of the tumor from the frontal sinus. Three girls aged 10, 15 and 18 years had osteofibrous dysplasia, with an osteolytic lesion located in the upper third of the tibia. The patient with osseous dysplasia was a 39year-old woman with a jaw lesion, in contact with one tooth. The patient with the post-traumatic fibro-osseous lesion of the ribs was a 51-year-old

Figure 1 Histological subtypes of fibrous dysplasia. (a-b) Conventional form, typical 'letters of the alphabet' immature bony trabeculae and fibrous paucicellular fibroblast-like background; (c) fibro-involutive form, abundant fibrous tissue with slight osteogenesis and edematous interstitial imbibition (d); (e) osteosclerosing form, abundant Pagetoid-like osteogenesis and paucicellular fibrous tissue; (f) osteocartilaginous form, lobules of hyaline cartilage with peripheral enchondral ossification; (g) cementifying form, fibrous cellular tissue with small spherules of cementum-like material; (h) aneurysmal cystic form, hemorrhagic suffusion surrounded by osteoclast-like giant cells. 

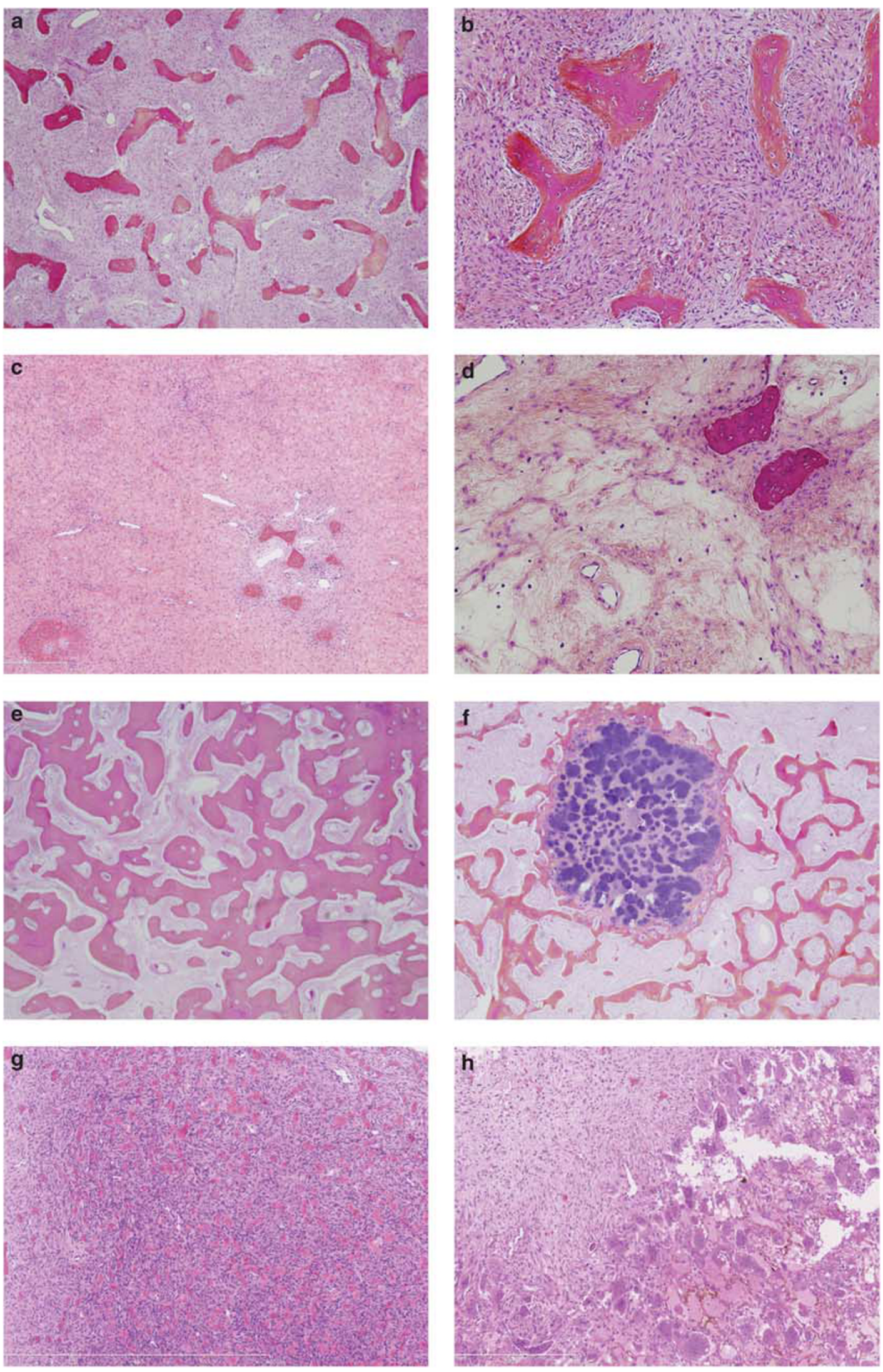
Table 2 Clinical and pathological findings and GNAS mutation status in patients with fibrous dysplasia

\begin{tabular}{|c|c|c|c|c|c|c|c|}
\hline no. & $\begin{array}{l}\text { GNAS } \\
\text { mutation } \\
\text { (exon 8) }\end{array}$ & Sex & $\begin{array}{c}\text { Age } \\
\text { (years) }\end{array}$ & Site & $\begin{array}{l}\text { Material for } \\
\text { molecular analysis }\end{array}$ & Molecular detection of GNAS mutations & $\begin{array}{l}\text { Histological } \\
\text { subtype }\end{array}$ \\
\hline 1 & R201C & $\mathrm{F}$ & 20 & Femur & Paraffin block and frozen sample & High-resolution melting, direct sequencing (exon 8) & Conventional \\
\hline 2 & R201C & M & 51 & Radius & Frozen sample & High-resolution melting, allele-specific PCR, direct sequencing (exon 8) & Conventional \\
\hline 3 & R201C & $\mathrm{F}$ & 10 & Femur & Paraffin block and frozen sample & High-resolution melting, allele-specific PCR, direct sequencing (exon 8) & Fibro-involutive \\
\hline 4 & R201C & $\mathrm{F}$ & 10 & Maxilla & Paraffin block and frozen sample & High-resolution melting, allele-specific PCR, direct sequencing (exon 8) & Osteosclerosing \\
\hline 5 & R201C & $\mathrm{F}$ & 72 & Pubis & Paraffin block & High-resolution melting, direct sequencing (exon 8) & Conventional \\
\hline 6 & R201C & $\mathrm{F}$ & 14 & Skull & Paraffin block & High-resolution melting, allele-specific PCR, direct sequencing (exon 8) & Fibro-involutive \\
\hline 7 & R201C & $\mathrm{M}$ & 44 & NA & Paraffin block & Allele-specific PCR, direct sequencing (exon 8) & Fibro-involutive \\
\hline 8 & R201C & $\mathrm{F}$ & 54 & Femur & Paraffin block & Direct sequencing (exon 8 and 9) & Osteosclerosing \\
\hline 9 & R201C & $\mathrm{F}$ & 46 & Radius & Frozen sample & High-resolution melting, direct sequencing (exon 8) & Fibro-involutive \\
\hline 10 & R201C & $\mathrm{M}$ & 18 & Femur & Paraffin block & High-resolution melting, direct sequencing (exon 8) & Cementifying \\
\hline 11 & R201C & M & 54 & Femur & Paraffin block & High-resolution melting, direct sequencing (exon 8) & Fibro-involutive \\
\hline 12 & $\mathrm{R} 201 \mathrm{H}$ & $\mathrm{F}$ & 27 & Radius & Paraffin block and frozen sample & High-resolution melting, allele-specific PCR, direct sequencing (exon 8) & Conventional \\
\hline $13^{*}$ & $\mathrm{R} 201 \mathrm{H}$ & $\mathrm{F}$ & 12 & Femur & Paraffin block and frozen sample & High-resolution melting, allele-specific PCR, direct sequencing (exon 8) & Osteocartilaginous \\
\hline $14^{*}$ & $\mathrm{R} 201 \mathrm{H}$ & M & 48 & Femur & Paraffin block and frozen sample & High-resolution melting, allele-specific PCR, direct sequencing (exon 8) & Conventional \\
\hline 15 & $\mathrm{R} 201 \mathrm{H}$ & M & 26 & Humerus & Frozen sample & High-resolution melting, allele-specific PCR, direct sequencing (exon 8) & Fibro-involutive \\
\hline 16 & $\mathrm{R} 201 \mathrm{H}$ & $\mathrm{M}$ & 10 & Orbit & Frozen sample & High-resolution melting, allele-specific PCR, direct sequencing (exon 8) & Conventional \\
\hline 17 & $\mathrm{R} 201 \mathrm{H}$ & $\mathrm{M}$ & 15 & Orbit & Frozen sample & High-resolution melting, allele-specific PCR, direct sequencing (exon 8) & Aneurysmal cystic \\
\hline 18 & $\mathrm{R} 201 \mathrm{H}$ & $\mathrm{F}$ & 57 & Femur & Frozen sample & High-resolution melting, direct sequencing (exon 8) & Conventional \\
\hline 19 & $\mathrm{R} 201 \mathrm{H}$ & $\mathrm{F}$ & 57 & Femur & Paraffin block & High-resolution melting, direct sequencing (exon 8) & Osteosclerosing \\
\hline 20 & $\mathrm{R} 201 \mathrm{H}$ & $\mathrm{M}$ & 44 & Talus & Paraffin block & High-resolution melting, direct sequencing (exon 8) & Osteosclerosing \\
\hline 21 & $\mathrm{R} 201 \mathrm{H}$ & $\mathrm{F}$ & 31 & Femur & Paraffin block & Direct sequencing (exon 8 and 9) & Aneurismal cystic \\
\hline 22 & $\mathrm{R} 201 \mathrm{H}$ & $\mathrm{F}$ & 46 & Femur & Paraffin block & High-resolution melting, direct sequencing (exon 8) & Conventional \\
\hline 23 & $\mathrm{R} 201 \mathrm{H}$ & $\mathrm{F}$ & 12 & Maxilla & Paraffin block & High-resolution melting, direct sequencing (exon 8) & Conventional \\
\hline 24 & NIM & $\mathrm{M}$ & 42 & Femur & Paraffin block & High-resolution melting (exon 8) & Conventional \\
\hline 25 & NIM & $\mathrm{F}$ & 52 & Radius & Paraffin block & High-resolution melting, allele-specific PCR (exon 8) & Conventional \\
\hline 26 & NIM & M & 28 & Femur & Paraffin block & High-resolution melting (exon 8), allele-specific PCR (exon 8 and 9) & Fibro-involutive \\
\hline 27 & NIM & M & 13 & Femur & Paraffin block & High-resolution melting (exon 8), allele-specific PCR (exon 8 and 9) & Fibro-involutive \\
\hline 28 & NIM & M & 36 & Maxilla & Paraffin block and frozen sample & High-resolution melting (exon 8), allele-specific PCR (exon 8 and 9) & Conventional \\
\hline 29 & NIM & $\mathrm{F}$ & 45 & Pubis & Paraffin block and frozen sample & High-resolution melting (exon 8), allele-specific PCR (exon 8 and 9) & Conventional \\
\hline 30 & NIM & $\mathrm{M}$ & 12 & Rib & Paraffin block & High-resolution melting (exon 8) & Fibro-involutive \\
\hline 31 & NIM & $\mathrm{F}$ & 7 & Femur & Paraffin block & High-resolution melting (exon 8) & Osteosclerosing \\
\hline 32 & NIM & M & 19 & Femur & Frozen sample & High-resolution melting, direct sequencing (exon 8), allele-specific PCR (exon 8 and 9) & Aneurysmal cystic \\
\hline 33 & NIM & $\mathrm{F}$ & 32 & Metatarsus & Paraffin block & High-resolution melting, direct sequencing (exon 8) & Fibro-involutive \\
\hline 34 & NIM & $\mathrm{F}$ & 16 & Radius & Paraffin block & High-resolution melting, allele-specific PCR, direct sequencing (exon 8) & Fibro-involutive \\
\hline 35 & NIM & $\mathrm{F}$ & 30 & Tibia & Paraffin block & High-resolution melting (exon 8) & Aneurysmal cystic \\
\hline 36 & NIM & $\mathrm{F}$ & 27 & Skull & Paraffin block & High-resolution melting (exon 8) & Osteosclerosing \\
\hline 37 & NIM & $\mathrm{F}$ & 19 & NA & Frozen sample & High-resolution melting, allele-specific PCR, direct sequencing (exon 8) & NA \\
\hline 38 & NIM & $\mathrm{F}$ & 43 & Mandible & Paraffin block & High-resolution melting (exon 8) & Conventional \\
\hline 39 & NIM & $\mathrm{F}$ & 74 & Tibia & Frozen sample & High-resolution melting, allele-specific PCR (exon 8) & Fibro-involutive \\
\hline 40 & NIM & $\mathrm{F}$ & 26 & NA & Paraffin block & High-resolution melting, direct sequencing (exon 8), allele-specific PCR (exon 8 and 9) & NA \\
\hline 41 & NIM & $\mathrm{M}$ & 64 & Spine & Frozen sample & High-resolution melting (exon 8), allele-specific PCR (exon 8 and 9) & Osteosclerosing \\
\hline 42 & NIM & $\mathrm{F}$ & 22 & Frontal sinus & Frozen sample & High-resolution melting (exon 8), allele-specific PCR (exon 8 and 9) & Osteosclerosing \\
\hline 43 & NIM & $\mathrm{F}$ & 19 & NA & Paraffin block & High-resolution melting, allele-specific PCR (exon 8) & Conventional \\
\hline 44 & NIM & $\mathrm{F}$ & 27 & NA & Paraffin block & High-resolution melting (exon 8) & Conventional \\
\hline 45 & NIM & $\mathrm{M}$ & 23 & Skull & Paraffin block & High-resolution melting (exon 8) & Conventional \\
\hline 46 & NIM & $\mathrm{M}$ & 43 & NA & Paraffin block & High-resolution melting, allele-specific PCR (exon 8) & Fibro-involutive \\
\hline 47 & NIM & $\mathrm{F}$ & 51 & NA & Paraffin block & High-resolution melting, allele-specific PCR (exon 8) & Fibro-involutive \\
\hline 48 & NIM & M & 33 & Calcaneus & Paraffin block & Direct sequencing (exon 8 and 9) & Cementifying \\
\hline 49 & NIM & M & 49 & Tibia & Paraffin block & Direct sequencing (exon 8 and 9 ) & Conventional \\
\hline 50 & NIM & $\mathrm{M}$ & 21 & Tibia & Paraffin block & Direct sequencing (exon 8 and 9) & Cementifying \\
\hline 51 & NIM & $\mathrm{F}$ & 39 & Spine & Paraffin block & High-resolution melting, direct sequencing (exon 8) & Conventional \\
\hline
\end{tabular}

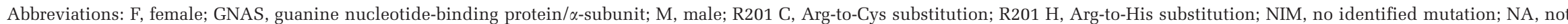
applicable; * polyostotic form. 
Table 3 Clinical and pathological findings in patients with positive and negative GNAS mutations

\begin{tabular}{lccc}
\hline & $\begin{array}{c}\text { Positive } \\
\text { fibrous } \\
\text { dysplasia } \\
\text { GNAS } \\
\text { mutations } \\
\text { (n=23) }\end{array}$ & $\begin{array}{c}\text { Negative } \\
\text { fibrous } \\
\text { dysplasia } \\
\text { GNAS } \\
\text { mutations } \\
\text { (n=28) }\end{array}$ & \\
& & & \\
\hline Sex & & & \\
Female & 14 & 14 & 0.44 \\
Male & 9 & 14 & \\
Age (years, mean \pm s.d.) & $34( \pm 19)$ & $33( \pm 16)$ & 0.90 \\
Site & & & \\
Craniofacial & 5 & 5 & \\
Extra-craniofacial & 17 & 17 & \\
NA & 1 & 6 & \\
Histological subtypes & & & \\
Conventional & 9 & 10 & 0.96 \\
Unconventional & 14 & 16 & \\
$\quad$ Fibro-involutive & 6 & 8 & \\
$\quad$ Aneurismal cystic & 2 & 2 & \\
Osteosclerosing & 4 & 4 & \\
Osteocartilaginous & 1 & 0 & \\
$\quad$ Cementifying & 1 & 2 & \\
NA & 0 & 2 & \\
& & &
\end{tabular}

Abbreviations: GNAS, guanine nucleotide-binding protein/ $\alpha$-subunit; NA, not applicable.

woman with a small mass on the anterior arch of the 11th rib.

Patients with low-grade osteosarcoma. Mean age of patients with low-grade osteosarcoma was 34 years (range 13-67 years) and the sex ratio was 0.7 (5 male and 7 female). Ten patients had parosteal low-grade osteosarcoma, two had centromedullary low-grade osteosarcoma and two had dedifferentiated lowgrade osteosarcoma. The most frequently observed site was the femur ( 8 out of 12 cases). All cases exhibited MDM2 amplification or overexpression, assessed by quantitative PCR and immunohistochemistry, respectively.

\section{Molecular Analysis}

Patients with fibrous dysplasia. The results of our study are summarized in Tables 2 and 3 . The percentage of GNAS mutations was $45 \%(23 / 51)$. All mutated cases were codon 201 mutations, with 12 Arg-to-His substitutions (R201H) and 11 Arg-toCys substitutions (R201C). No fibrous dysplasia cases were found mutated in exon 9 (eight cases tested by allele-specific PCR and three by direct sequencing). Of the 23 mutated cases, the mutation was found in 11 cases by allele-specific PCR and in 20 cases by HRM, all were confirmed by direct sequencing. Figure 2 shows one case of R201C and one case of $\mathrm{R} 201 \mathrm{H}$ GNAS mutation. The concordance between HRM and allele-specific PCR was $100 \%$ for the 25 cases tested using the two techniques, including 10 mutated and 15 nonmutated. No interpretation could be obtained for 13 samples, regardless of the techniques used. Nonconclusive results were attributed to the quality or quantity of gDNA extracted. GNAS mutation was detected in the same proportion of conventional fibrous dysplasia $(47 \%)$ as in unconventional histological subtypes $(47 \%, P=0.96)$, regardless of sex $(P=0.44)$, age $(P=0.90)$ and the location (craniofacial vs other location, $P=1$ ).

Patients with other benign fibro-osseous lesions (ossifying fibroma, osseous dysplasia, osteofibrous dysplasia, post-traumatic fibro-osseous lesion of the ribs) and low-grade osteosarcoma. GNAS mutations were not detected in any ossifying fibroma (12 by HRM and 9 by allele-specific PCR on exon 8 ) or osseous dysplasia, osteofibrous dysplasia and the post-traumatic fibro-osseous lesion of the ribs (5 cases tested by HRM on exon 8).

GNAS mutations were not detected in any lowgrade osteosarcoma (14 by HRM and 13 by allelespecific PCR on exon 8, 13 of whom were tested by both the techniques with a concordance rate of $100 \%$ ).

\section{Discussion}

Fibrous dysplasia is a benign fibro-osseous lesion that can easily be diagnosed when the clinical and radiological presentations are classical, not necessarily requiring morphological study if the lesion is discovered fortuitously and is asymptomatic. ${ }^{42,43}$ Therefore, only 'atypical' lesions are biopsied and can present a diagnostic challenge for pathologists, because of the frequent existence of histological variations, modifying the classical archetype of fibrous dysplasia, especially with the absence of the typical 'alphabetic' woven bone pattern. This can make the differential diagnosis between fibrous dysplasia and other benign fibro-osseous lesions or low-grade osteosarcoma difficult.

Lee et $a l^{39}$ recently published a meta-analysis including 155 reported cases of fibrous dysplasia from 8 studies and 48 additional fibrous dysplasia cases from his institution. He assessed the incidence and types of GNAS mutations. The overall positive rate of GNAS mutations in fibrous dysplasia was $71.9 \%(146 / 203)$. It is of note that the frequency varied according to the molecular method employed. Indeed, the sensitivity of detection of GNAS mutations varied from $23.1 \%(3 / 13)$ to $100 \%$ (16/16) with PCR-restriction fragment-length polymorphism, ${ }^{36,37} 58.3 \%(28 / 48)$ to $88 \%$ (8/9) with direct sequencing, ${ }^{39,41} 67.1 \%$ (51/76) with mutation-specific restriction enzyme digestion, ${ }^{32}$ $100 \%$ (8/8) with protein nucleic acid-mediated PCR, ${ }^{44} 100 \%(9 / 9)$ with restriction digestion analysis and direct sequencing, ${ }^{38}$ and $96 \%$ (23/24) with pyrosequencing. ${ }^{41}$ The most common GNAS 

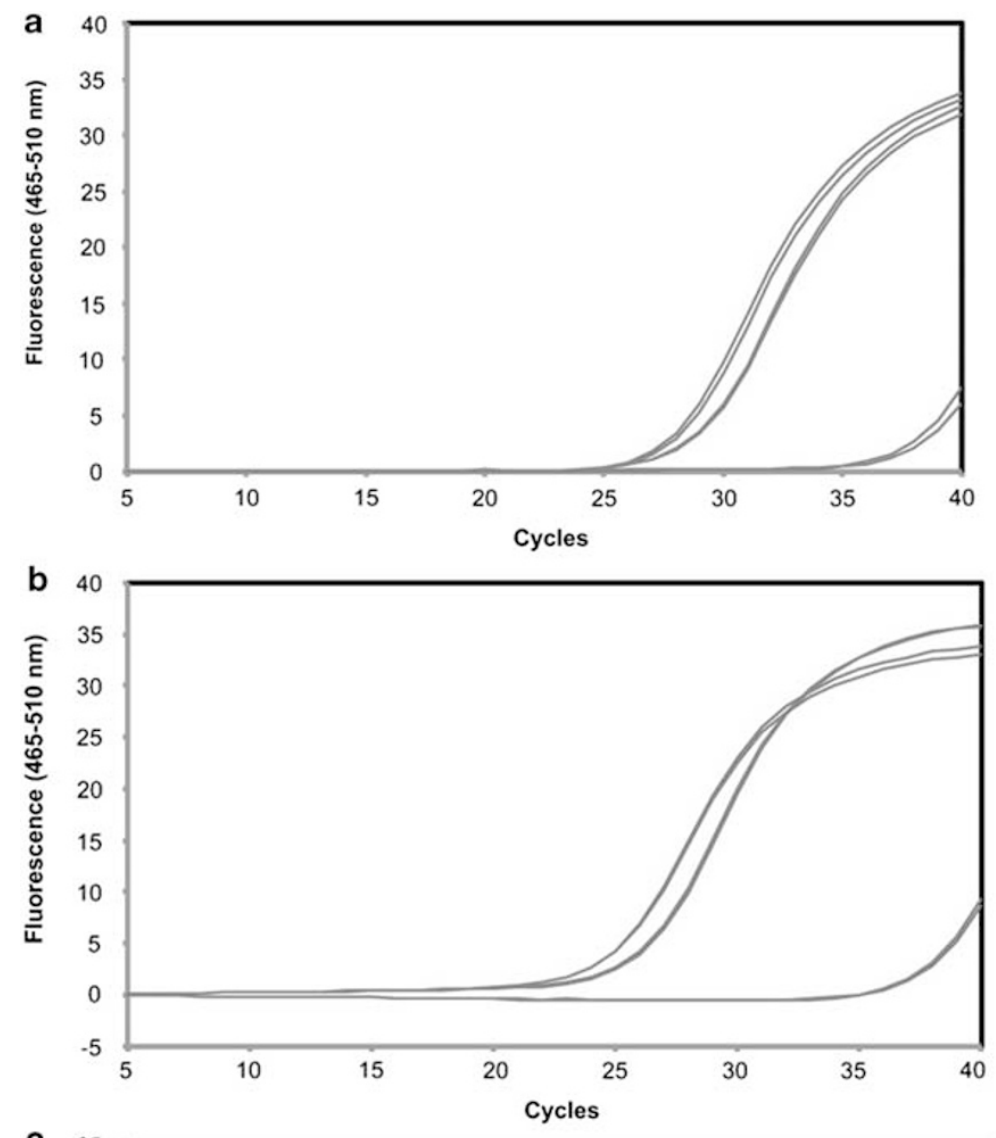

d
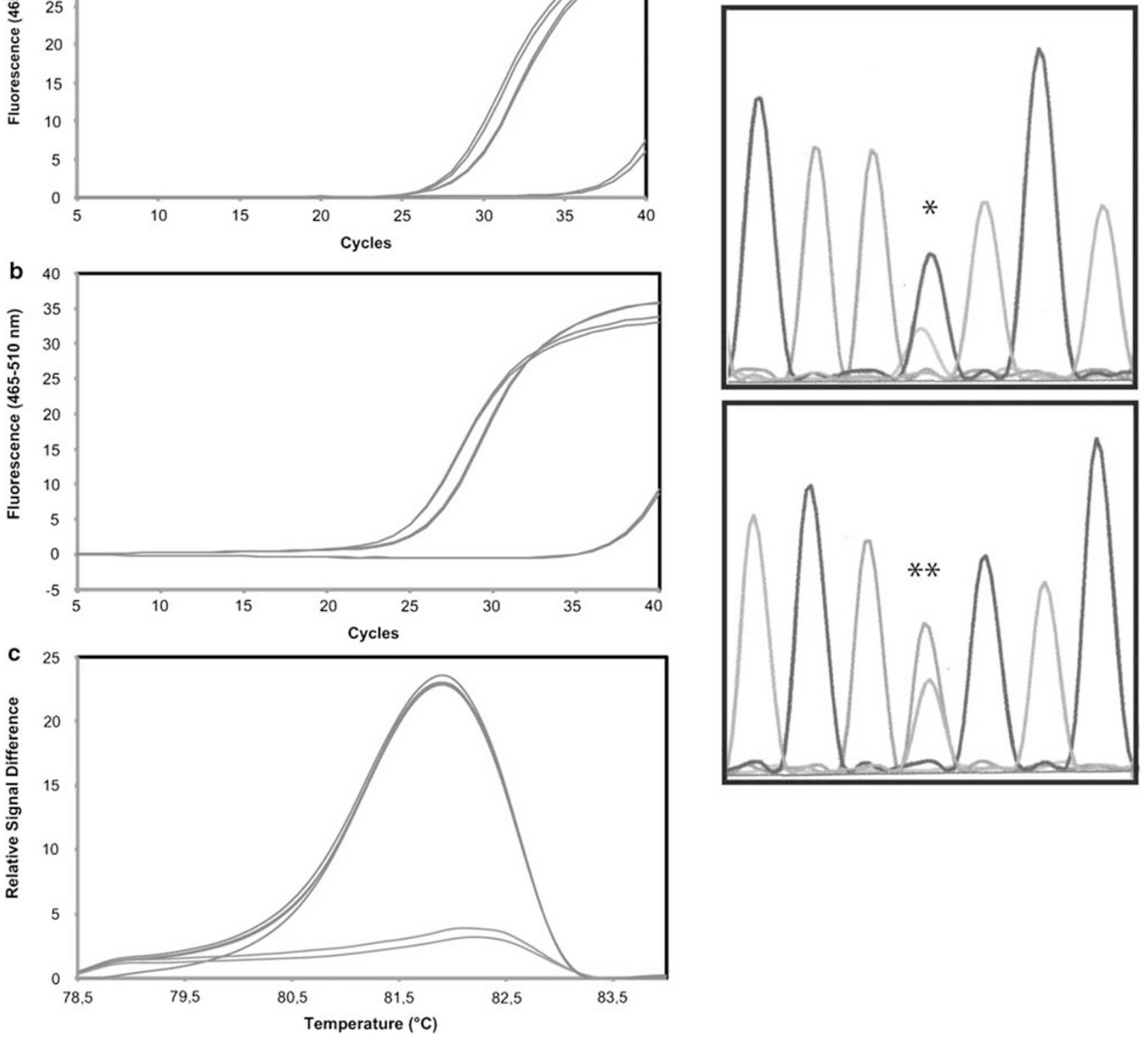

Figure 2 Mutational analysis of genomic DNA isolated from fibrous dysplasia tissue: three different molecular methods of detection of GNAS (guanine nucleotide-binding protein/ $\alpha$-subunit) mutations on exon 8. (a) R201C allele-specific PCR and (b) R201H allele-specific PCR: detection of PCR products in real time after hybridization of the specific primer with the complementary DNA target, ending with the substituted nucleotide; (c) High-resolution melting on exon 8: distinct melting curve of GNAS mutations in a patient and a positive control (red curve) compared with the wild-type allele (negative control, blue curve); (d) Direct sequencing on exon 8: CGT >CAT (p.R201H: Arg-to-His substitution *) and CGT > TGT (p.R201C: Arg-to-Cys substitution **). The color reproduction of this figure is available on the Modern Pathology journal online.

mutations by far were $\mathrm{R} 201 \mathrm{H}(66.4 \%, 95 / 143)$ and R201C $(30.8 \%, 44 / 143)$ on exon 8 , followed by only three cases of Q227L mutation $(2.1 \%$, exon 9$)$ and one case of R201S mutation ( $0.7 \%$, exon 8$)$. In our study, GNAS mutations were detected in $45 \%$ $(23 / 51)$ cases of fibrous dysplasia $(52 \% \mathrm{R} 201 \mathrm{H}$ and $48 \%$ R201C). Interestingly, we obtained identical frequencies for HRM, allele-specific PCR and direct sequencing. The incidence of the mutation was thus lower than described in the literature. Regardless of the molecular detection method used, this suggested a low sensitivity of detection of GNAS mutations in fibrous dysplasia. Such a result could be explained by the existence of mosaicism, with the coexistence within the lesion of mutant and non-mutant cells in varying amounts. ${ }^{18}$ This particular distribution of mutant cells could result from a post-zygotic GNAS mutation that generated not only somatic mosaicism 
throughout the body (McCune-Albright syndrome, polyostotic fibrous dysplasia), ${ }^{45,46}$ but also somatic mosaicism of normal and mutant osteogenic cells within the lesion. ${ }^{47}$ Mutated cells in the different organs derived from a single clone originating from an ancestral cell mutated during in utero development that could contribute to the three embryonic germ layers. ${ }^{18,48}$ On the basis of in vivo experiments, Bianco et $a l^{19}$ showed that only a mixture of mutant and non-mutant skeletal stem cells could reproduce fibrous dysplasia tissue when transplanted in immunocompromised mice. These findings suggested that the coexistence of mutant and non-mutant cells was required for the survival of mutant cells and for the development of fibrous dysplasia. However, the critical mutational load necessary to generate fibrous dysplasia tissue remains unknown. The low detection of GNAS mutation could also be explained by a 'normalization' of fibrous dysplasia cells over time, due to a high level of apoptosis of mutant skeletal stem cells, compared with non-mutant stem cells. ${ }^{49}$ Mutant stem cells and osteogenic cells had an accelerated cell cycle compared with non-mutant cells. This accelerated turnover led to 'sterilization' of the fibrous dysplasia lesions in older patients, which could explain why mutated cells may become undetectable. ${ }^{49,50}$ Because of the dynamic nature of this mosaic pattern, the proportion of mutant cells may differ greatly within the lesion, particularly in older lesions. This prompted the use of a highly sensitive molecular technique for the detection of GNAS mutations and this could mean that the GNAS mutation would be difficult to find in older patients. However, this hypothesis has not been validated by other studies. ${ }^{39}$ This was also the case in the present study, in which the average age of patients was not significantly different in the 'mutated' and 'not mutated' groups.

Different strategies have been settled to characterize mutations from clinical DNA samples. Although cost effectiveness is a point to consider, sensitivity must be the major determinant of the choice. Here, all experimental data favored a strategy based on the use of HRM for screening, followed by sequencing for the precise determination of the mutation. The use of allele-specific PCR, which could be less expensive than HRM for a unique mutated allele, needs to be repeated for three alleles. This has a cost, especially for rare clinical material.

With HRM, it was possible to be specific and it was thus proved to be sensitive to detect only known mutations in a defined exon (exon 8), other exons not being routinely studied. Allele-specific PCR appeared even more specific, although involving a single probe designed for each mutation. Restriction fragment-length polymorphism had the same limitations and not all mutations could be detected using this technique. As HRM, direct sequencing provided the greatest number of details of the sequence covering all possible mutations on the exon examined, but was less sensitive, with a threshold of $20 \%$ of mutant cells in the sample. ${ }^{41}$ With protein acid-mediated PCR, the specific primer for exon 8 allowed the selective amplification of a low copy number of a mutant allele. ${ }^{44}$ With this molecular technique, Lietman et $a l^{30}$ were able to detect one mutant GNAS allele out of 1000-5000 cells. However, in their study, gDNA was extracted from peripheral blood, mainly from patients with McCune-Albright syndrome and not from fibrous dysplasia tissue. The most sensitive method described for the detection of GNAS mutations in fibrous dysplasia to date is pyrosequencing. ${ }^{41}$ Pyrosequencing should therefore be considered in routine diagnostic use, as this technique does not require large amounts of DNA. The main pitfall is the quality of the DNA, which is difficult for bone material. Liang et $a{ }^{41}$ described a fibrous dysplasia series in which $96 \%(23 / 24)$ of cases of fibrous dysplasia were positive for GNAS mutations at codon 201 (19 R201H and 4 R201C). The authors evaluated the sensitivity of pyrosequencing using a premixture of varying ratios of mutant and wild-type control oligonucleotides before the PCR reaction. They evaluated the correlation between the quantitative results and the calculated ratio in the starting materials. Mutant alleles as low as 5\% could be detected in the sample (vs 20\% with Sanger sequencing), as reported in the literature for the KRAS mutation, eg, Ogino et al. ${ }^{51}$ Pyrosequencing was designed to detect only the two common mutations of codon 201. In our study, we were limited by low DNA extraction yields for $49 \%$ (40/81) of formalin-fixed, paraffin-embedded tissues, whereas all frozen samples were of appropriate quality DNA for molecular analyses (18/18). All of formalin-fixed, paraffin-embedded specimens received acidic pretreatment to decalcify bones, which is known to affect DNA and mRNA integrity. ${ }^{32}$ EDTA decalcification, ${ }^{52}$ in particular if combined with ultrasonic decalcification, ${ }^{53}$ might increase the quality of the DNA extracted. However, the duration of such a decalcification protocol might make it difficult to implement in routine, apart from implementing in specialized centers.

To confirm the extent and variability of the original material for the outcome of the molecular testing, we next investigated GNAS mutations on both formalin-fixed and paraffin-embedded, and frozen samples for eight cases of fibrous dysplasia. In one case, the mutation was found in formalin-fixed and paraffin-embedded material, and not in the frozen sample, two cases did not show mutations on either formalin-fixed and paraffin-embedded or frozen samples, in three cases mutation was found on frozen samples and not on formalin-fixed and paraffin-embedded tissues, and two showed mutations on frozen samples with no analyzable gDNA on formalin-fixed and paraffin-embedded tissues.

What might distinguish our study was that it mostly addressed unconventional fibrous dysplasia 
subtypes, which was a challenge to the pathologist in terms of routine activity. Most other published studies have only investigated typical fibrous dysplasia, ${ }^{32,37,39,41}$ not representative of the fibro-osseous lesions examined by pathologists. We looked for GNAS mutations in 51 cases of fibrous dysplasia, including 30 unconventional morphologically affected fibrous dysplasia subtypes (Table 3). The same proportions of GNAS mutations were found in the conventional fibrous dysplasia (47\%) and other subtypes (47\%). As controls, we investigated 26 cases of benign fibroosseous lesions and 14 cases of low-grade osteosarcoma; no cases of GNAS mutation were found (exon 8), confirming the specificity of the GNAS mutation in fibro-osseous lesions.

In conclusion, we confirmed that GNAS mutations were specific to fibrous dysplasia among all fibroosseous lesions. Regardless of the molecular methods used in this study (HRM analysis, DNA sequencing and allele-specific PCR), a large number of fibrous dysplasia were not associated with a GNAS mutation. Those cases of fibrous dysplasia without detectable GNAS mutation may be explained by the tumoral mosaicism of fibrous dysplasia, with low rates of mutated cells compared with non-mutated cells, or by the existence of new mutations, which were not sought in our study. We nevertheless concluded that testing for GNAS mutations, preferably on cryopreserved material, might, despite the low sensitivity, constitute an important complementary diagnostic tool, particularly with the unconventional, morphologically changed subtypes of fibrous dysplasia. However, the absence of the GNAS mutation in a case of fibro-osseous lesions should not rule out the diagnosis of fibrous dysplasia.

\section{Disclosure/conflict of interest}

The authors declare no conflicts of interest.

\section{References}

1 Brannon RB, Fowler CB. Benign fibro-osseous lesions: a review of current concepts. Adv Anat Pathol 2001; 8:126-143.

2 Slootweg PJ. Lesions of the jaws. Histopathology 2009;54:401-418.

3 Campanacci M, Laus M. Osteofibrous dysplasia of the tibia and fibula. J Bone Joint Surg Am 1981;63: 367-375.

4 Slootweg PJ. Maxillofacial fibro-osseous lesions: classification and differential diagnosis. Semin Diagn Pathol 1996;13:104-112.

5 Franceschina MJ, Hankin RC, Irwin RB. Low-grade central osteosarcoma resembling fibrous dysplasia. A report of two cases. Am J Orthop 1997;26:432-440.

6 Muramatsu K, Hashimoto T, Seto S, et al. Low-grade central osteosarcoma mimicking fibrous dysplasia: a report of two cases. Arch Orthop Trauma Surg 2008; 128:11-15.
7 Alawi F. Benign fibro-osseous diseases of the maxillofacial bones. A review and differential diagnosis. Am J Clin Pathol 2002;118(Suppl):S50-S70.

8 Lee J, Fitzgibbon E, Chen Y, et al. Clinical guidelines for the management of craniofacial fibrous dysplasia. Orphanet J Rare Dis 2012;7(Suppl 1):S2.

9 Dorfman HD. New knowledge of fibro-osseous lesions of bone. Int J Surg Pathol 2010;18(Suppl 3):S62-S65.

10 Eversole R, Su L, ElMofty S. Benign fibro-osseous lesions of the craniofacial complex. A review. Head Neck Pathol 2008;2:177-202.

11 Patel MM, Wilkey JF, Abdelsayed R, et al. Analysis of GNAS mutations in cemento-ossifying fibromas and cemento-osseous dysplasias of the jaws. Oral Surg Oral Med Oral Pathol Oral Radiol Endod 2010;109:739-743.

12 Albright FBA, Hampton AO, Smith P. Syndrome characterized by osteitis fibrosa disseminata, areas of pigmentation and endocrine dysfunction with precocious puberty in females. N Engl J Med 1937;216: 727-746.

13 Lichtenstein L. Polyostotic fibrous dysplasia. Arch Surg 1938;36:874-879.

14 Lichtenstein L, Jaffe HL. Fibrous dysplasia of bone: a condition affecting one, several or many bones, the graver cases of which may present abnormal pigmentation of skin, premature sexual development, hyperthyroidism and still other extraskeletal abnormalities. Arch Pathol 1942;33:777-797.

15 Mazabraud A, Semat P, Roze R. [Apropos of the association of fibromyxomas of the soft tissues with fibrous dysplasia of the bones]. Presse Med 1967;75:2223-2228.

16 Szendroi M, Rahoty P, Antal I, et al. Fibrous dysplasia associated with intramuscular myxoma (Mazabraud's syndrome): a long-term follow-up of three cases. J Cancer Res Clin Oncol 1998;124:401-406.

17 Kabukcuoglu F, Kabukcuoglu Y, Yilmaz B, et al. Mazabraud's syndrome: intramuscular myxoma associated with fibrous dysplasia. Pathol Oncol Res 2004;10:121-123.

18 Happle R. The McCune-Albright syndrome: a lethal gene surviving by mosaicism. Clin Genet 1986;29:321-324.

19 Bianco P, Kuznetsov SA, Riminucci M, et al. Reproduction of human fibrous dysplasia of bone in immunocompromised mice by transplanted mosaics of normal and Gsalpha-mutated skeletal progenitor cells. J Clin Invest 1998;101:1737-1744.

20 Robey PG, Kuznetsov S, Riminucci M, et al. The role of stem cells in fibrous dysplasia of bone and the Mccune-Albright syndrome. Pediatr Endocrinol Rev 2007;4(Suppl 4):386-394.

21 Okamoto S, Hisaoka M, Ushijima M, et al. Activating Gs(alpha) mutation in intramuscular myxomas with and without fibrous dysplasia of bone. Virchows Arch 2000;437:133-137.

22 Marie P. [Cellular and molecular biology of fibrous dysplasia]. Ann Pathol 2001;21:489-498.

23 Weinstein LS, Shenker A, Gejman PV, et al. Activating mutations of the stimulatory $\mathrm{G}$ protein in the McCuneAlbright syndrome. N Engl J Med 1991;325:1688-1695.

24 Schwindinger WF, Francomano CA, Levine MA. Identification of a mutation in the gene encoding the alpha subunit of the stimulatory $G$ protein of adenylyl cyclase in McCune-Albright syndrome. Proc Natl Acad Sci USA 1992;89:5152-5156.

25 Shenker A, Weinstein LS, Sweet DE, et al. An activating Gs alpha mutation is present in fibrous 
dysplasia of bone in the McCune-Albright syndrome. J Clin Endocrinol Metab 1994;79:750-755.

26 Delaney D, Diss TC, Presneau N, et al. GNAS1 mutations occur more commonly than previously thought in intramuscular myxoma. Mod Pathol 2009;22:718-724.

27 Alman BA, Greel DA, Wolfe HJ. Activating mutations of Gs protein in monostotic fibrous lesions of bone. J Orthop Res 1996;14:311-315.

28 Candeliere GA, Roughley PJ, Glorieux FH. Polymerase chain reaction-based technique for the selective enrichment and analysis of mosaic arg201 mutations in G alpha s from patients with fibrous dysplasia of bone. Bone 1997;21:201-206.

29 Gorelov VN, Dumon K, Barteneva NS, et al. Overexpression of Gs alpha subunit in thyroid tumors bearing a mutated Gs alpha gene. J Cancer Res Clin Oncol 1995;121:219-224.

30 Lietman SA, Ding C, Levine MA. A highly sensitive polymerase chain reaction method detects activating mutations of the GNAS gene in peripheral blood cells in McCune-Albright syndrome or isolated fibrous dysplasia. J Bone Joint Surg Am 2005;87:2489-2494.

31 Riminucci M, Fisher LW, Majolagbe A, et al. A novel GNAS1 mutation, R201G, in McCune-albright syndrome. J Bone Miner Res 1999;14:1987-1989.

32 Idowu BD, Al-Adnani M, O’Donnell $\mathrm{P}$, et al. A sensitive mutation-specific screening technique for GNAS1 mutations in cases of fibrous dysplasia: the first report of a codon 227 mutation in bone. Histopathology 2007;50:691-704.

33 Marie PJ, de Pollak C, Chanson P, et al. Increased proliferation of osteoblastic cells expressing the activating Gs alpha mutation in monostotic and polyostotic fibrous dysplasia. Am J Pathol 1997;150:1059-1069.

34 Sakamoto A, Oda Y, Iwamoto Y, et al. A comparative study of fibrous dysplasia and osteofibrous dysplasia with regard to expressions of c-fos and c-jun products and bone matrix proteins: a clinicopathologic review and immunohistochemical study of c-fos, c-jun, type I collagen, osteonectin, osteopontin, and osteocalcin. Hum Pathol 1999;30:1418-1426.

35 Yamamoto T, Ozono K, Kasayama S, et al. Increased IL-6-production by cells isolated from the fibrous bone dysplasia tissues in patients with McCune-Albright syndrome. J Clin Invest 1996;98:30-35.

36 Sakamoto A, Oda Y, Iwamoto Y, et al. A comparative study of fibrous dysplasia and osteofibrous dysplasia with regard to Gsalpha mutation at the Arg201 codon: polymerase chain reaction-restriction fragment length polymorphism analysis of paraffin-embedded tissues. J Mol Diagn 2000;2:67-72.

37 Toyosawa S, Yuki M, Kishino M, et al. Ossifying fibroma vs fibrous dysplasia of the jaw: molecular and immunological characterization. Mod Pathol 2007;20: 389-396.

38 Pollandt K, Engels C, Kaiser E, et al. Gsalpha gene mutations in monostotic fibrous dysplasia of bone and fibrous dysplasia-like low-grade central osteosarcoma. Virchows Arch 2001;439:170-175.
39 Lee SE, Lee EH, Park H, et al. The diagnostic utility of the GNAS mutation in patients with fibrous dysplasia: meta-analysis of 168 sporadic cases. Hum Pathol 2012;43:1234-1242.

40 Mariot V, Wu JY, Aydin C, et al. Potent constitutive cyclic AMP-generating activity of XLalphas implicates this imprinted GNAS product in the pathogenesis of McCune-Albright syndrome and fibrous dysplasia of bone. Bone 2011;48:312-320.

41 Liang Q, Wei M, Hodge L, et al. Quantitative analysis of activating alpha subunit of the $\mathrm{G}$ protein (Gsalpha) mutation by pyrosequencing in fibrous dysplasia and other bone lesions. J Mol Diagn 2011;13:137-142.

42 DiCaprio MR, Enneking WF. Fibrous dysplasia. Pathophysiology, evaluation, and treatment. J Bone Joint Surg Am 2005;87:1848-1864.

43 Chapurlat RD, Orcel P. Fibrous dysplasia of bone and McCune-Albright syndrome. Best Pract Res Clin Rheumatol 2008;22:55-69.

44 Bianco P, Riminucci M, Majolagbe A, et al. Mutations of the GNAS1 gene, stromal cell dysfunction, and osteomalacic changes in non-McCune-Albright fibrous dysplasia of bone. J Bone Miner Res 2000;15:120-128.

45 Shenker A, Weinstein LS, Moran A, et al. Severe endocrine and nonendocrine manifestations of the McCune-Albright syndrome associated with activating mutations of stimulatory G protein GS. J Pediatr 1993;123:509-518.

46 Shenker A. Chanson P, Weinstein LS, et al. Osteoblastic cells derived from isolated lesions of fibrous dysplasia contain activating somatic mutations of the Gs alpha gene. Hum Mol Genet 1995;4:1675-1676.

47 Riminucci M, Fisher LW, Shenker A, et al. Fibrous dysplasia of bone in the McCune-Albright syndrome: abnormalities in bone formation. Am J Pathol 1997;151:1587-1600.

48 Weinstein LS. G(s)alpha mutations in fibrous dysplasia and McCune-Albright syndrome. J Bone Miner Res 2006;21(Suppl 2):S120-S124.

49 Kuznetsov SA, Cherman N, Riminucci M, et al. Age-dependent demise of GNAS-mutated skeletal stem cells and 'normalization' of fibrous dysplasia of bone. J Bone Miner Res 2008;23:1731-1740.

50 Sissons HA, Malcolm AJ. Fibrous dysplasia of bone: case report with autopsy study 80 years after the original clinical recognition of the bone lesions. Skeletal Radiol 1997;26:177-183.

51 Ogino S, Kawasaki T, Brahmandam M, et al. Sensitive sequencing method for KRAS mutation detection by Pyrosequencing. J Mol Diagn 2005;7:413-421.

52 Alers JC, Krijtenburg PJ, Vissers KJ, et al. Effect of bone decalcification procedures on DNA in situ hybridization and comparative genomic hybridization. EDTA is highly preferable to a routinely used acid decalcifier. J Histochem Cytochem 1999;47:703-710.

53 Reineke T, Jenni B, Abdou MT, et al. Ultrasonic decalcification offers new perspectives for rapid FISH, DNA, and RT-PCR analysis in bone marrow trephines. Am J Surg Pathol 2006;30:892-896. 